\title{
Anti-sperm antibodies in homosexual men: prevalence and correlation with sexual behaviour
}

\author{
B P Mulhall, S Fieldhouse, S Clark, L Carter, L Harrison, B Donovan, R V Short
}

\begin{abstract}
The sera of 60 homosexual males were examined for the presence of antibodies to sperm using an indirect immunobead test (IBT). Six of $60(10 \%)$ had antibodies of IgG isotype; in addition two of the six had antibodies of IgA isotype. The presence of antibodies was associated with the practice of unprotected receptive anal intercourse in the previous six months. Antibodies were not found in homosexual men who were celibate, or who practised only oral intercourse during the same period. There was no correlation between the presence of anti-sperm antibodies and antibodies to human immunodeficiency virus (HIV), or numbers of $T$ lymphocytes. These preliminary results lend support to the hypothesis that antigen presentation in the lower gut may be a source of sensitisation against sperm. The possibility that anti-sperm antibodies may be a marker of receptive anal intercourse merits further investigation.
\end{abstract}

Antibodies to various components of sperm and seminal plasma are present in the sera of certain individuals, particularly vasectomised men and infertile couples, and there has been much speculation over their pathogenetic role. ${ }^{1}$ Recently, using a variety of methods, anti-sperm antibodies have also been detected in the sera of healthy homosexual men, or those who presented with HIV infection, ${ }^{2-5}$ or (other) sexually transmitted diseases. ${ }^{6}$ Together with data from experimental animal modes, ${ }^{78}$ therefore, it has been suggested that the introduction of spermatozoa into the rectum may lead to the development

Burnet Clinical Research Unit, Walter and Eliza Hall Institute of Medical Research, Melbourne

B P Mulhall, S Clark, L Harrison

HIV Service, Royal Melbourne Hospital, Parkville, Victoria

L Carter

Department of Physiology, Monash University, Melbourne

S Fieldhouse, R V Short

Department of Public Health, University of Sydney, Australia

B Donovan of a humoral immune response. However, many of these earlier studies either lacked information on the subjects' HIV status or used methods for measuring sperm antibodies that were only poorly reproducible, and with the exception of one study ${ }^{9}$ did not attempt to correlate the findings with specific sexual practices. A recent editorial stated that the most useful assay for anti-sperm antibodies is the immunobead method ${ }^{10}$ and this prompted us to use this technique to investigate sperm antibody titre and prevalence in a group of well documented homosexual men, to see to what extent it is correlated with recent sexual behaviour, HIV status, and indices of immune function.

\section{Patients}

Between January and March 1988, sixty four homosexuals (range 28-60 yr, mean 40.7) attending the Royal Melbourne Hospital HIV clinic as part of an ongoing epidemiological study ${ }^{11}$ completed questionnaires on their sexual practices over the previous six months. Based on their responses men were categorised into the following groups: Group 1unprotected oral intercourse only ( $n=13$ ), Group 2 -unprotected oral and anal intercourse $(n=39)$, Group 3-unprotected anal intercourse only $(n=2)$, and Group 4 -celibate $(n=6)$.

All individuals in the first three groups were recipients of sperm; six men who reported always using condoms during the previous six months were excluded from the study. On the basis of informed consent, blood was obtained for anti-sperm and antiHIV antibody testing as well as for quantitation of lymphocyte subsets. In addition sera were obtained from two homosexual men who had attended the Melbourne Sexually Transmissible Diseases Centre for treatment of rectal gonorrhoea; these were placed in Group 2.

\section{Methods}

Fresh donor sperm was obtained from volunteers. These were HIV antibody negative heterosexual men who were regular sperm donors in an in-vitro fertilisation program. Test sera were screened for antisperm antibodies using a minor modification of the indirect immunobead assay previously described. ${ }^{12}$ 
This is essentially a rosetting technique: briefly, serum at a dilution of $1: 10$ was incubated for $30 \mathrm{~min}$ at $37^{\circ} \mathrm{C}$ with live sperm (count $>60 \times 10^{6} / \mathrm{ml}$ and motility $>50 \%$ ) from donors who were anti-sperm antibody negative (determined by incubation of sperm with IgG or IgA coated immunobeads in the absence of serum). After washing to remove free immunoglobulin, the sperm were added to immunobeads coated with rabbit anti-human IgG or IgA (Biorad, Ca), and under magnification $(\times 25)$, 100 motile sperm were counted. The result was considered positive if $>10 \%$ of motile sperm had two or more beads attached. In each assay positive and negative control sera were included. Positive control sera were obtained from heterosexual men attending an infertility clinic. To minimise interassay variation results were expressed relative to a positive control value of $100 \%$. In addition, all positive samples were precipitated with PEG, ammonium sulphate, and more specifically, anti IgG or IgA coated beads, to check that anti-sperm activity resided in the immunoglobulin fraction. All positive sera were also serially diluted to determine antisperm antibody titre. Sera were screened for antibodies to HIV using an ELISA assay and confirmed by Western Blot. At the same time absolute numbers of $\mathrm{CD} 4+$ and $\mathrm{CD} 8+\mathrm{T}$ lymphocytes were determined using the monoclonal antibodies Leu 3a and Leu 2 (Becton Dickinson, $\mathrm{Ca}$ ) and flow cytometry (Coulter Epics IV, Ca).

\section{Results}

Six of $60(10 \%)$ sera tested positive for antibodies to sperm. All six had antibodies of IgG isotype; two of the six also had antibodies of IgA isotype. For IgG, three sera were positive at a dilution of $1: 100$ and the remaining three at a dilution of 1:50. The positive control sera were positive at a dilution of 1:500. For IgA, titres were lower in controls $(1: 200)$ and in patients (1:50). Anti-sperm activity was completely removed in all cases by precipitation with coated beads. Three different sperm donors were used and the inter-donor variation was less than $5 \%$.

All six subjects positive for anti-sperm antibodies were from Groups 2 and 3 (table 1), viz. they practised receptive anal intercourse; none of the thirteen recipients of oral intercourse alone had

Table 1 Anti-sperm antibodies and sexual practice

\begin{tabular}{lllc}
\hline & \multicolumn{2}{c}{ Receptive anal intercourse } \\
\cline { 2 - 4 } & & Yes & No \\
\hline Anti-sperm antibody status & +ve & 6 & 0 \\
& - ve & 35 & 19 \\
\hline
\end{tabular}

Anti-sperm antibodies detected in the immunobead test compared with sexual practices as determined by questionnaire.
Table 2 Anti-sperm antibodies and HIV status

\begin{tabular}{llcc}
\hline & \multicolumn{3}{c}{ HIV status } \\
\cline { 2 - 4 } & & $+v e$ & $-v e$ \\
\hline Anti-sperm antibody status & + ve & 2 & 4 \\
& - ve & 28 & 26
\end{tabular}

Anti-sperm antibodies compared with the presence of antibodies to HIV.

antisperm antibodies. Thirty subjects had antibodies to HIV; clinically they were all asymptomatic, that is, they belonged to the Centers for Disease Control (CDC) Groups II and III. ${ }^{13}$ Of the six antisperm antibody positive sera, two were positive and four negative for antibodies to HIV (table 2). However, given the small numbers, none of these results attained statistical significance (chi square test with Yates's correction and Fisher's exact test). There was a highly significant difference in indices of immune function between the HIV seropositive and seronegative groups with respect to absolute numbers of $\mathrm{CD} 4+(\mathrm{p}<0.01)$ and CD8 + $(\mathrm{p}<0.005) \mathrm{T}$ lymphocytes but not between anti-sperm antibody positive and negative subjects. There were no significant differences in age between any of the groups.

\section{Discussion}

The prevalence of antibodies to sperm in this group of homosexual men was $10 \%$, and was confined to $17 \%$ of those who had practised unprotected anal receptive intercourse in the previous six months. Other investigations using different methods have found prevalence rates of $20-50 \%$ in similar groups, ${ }^{2-7}$ although their studies were performed earlier in the HIV epidemic, before the availability of HIV testing, and when subjects were more likely to have practised unprotected anal receptive intercourse more frequently. In addition "naturally occurring" antibodies have been detected in the general male and female population. ${ }^{115}$ Previous methods for detecting anti-sperm antibodies have included sperm immobilisation, agglutination, indirect immunofluorescence, enzyme-linked immunosorbent assays (ELISA) and Western blotting, and have been striking in their lack of consistency and correlation, particularly when different target sperm preparations were used..$^{16}$ In the present study, employing the immunobead test, the variation between three different sperm donors was less than $5 \%$. However there is every likelihood that the antibodies recognised in the immunobead test are different from those detected in previous assays. In addition, the prevalence of these antibodies in the heterosexual population has not been fully investigated.

Experimental studies in rabbits have demon- 
strated that non-traumatic weekly deposition of sperm in the rectum leads to the formation of IgG and IgA reactive with rabbit sperm, associated circulating immune complexes, and antibody to the sperm component asialo GMI. ${ }^{78}$ In these experiments certain in vitro immune responses were depressed, ${ }^{8}$ and indeed there have been other suggestions that sperm and seminal plasma are immunosuppressive, ${ }^{17-20}$ possible because $T$ lymphocytes and sperm share common antigens. ${ }^{21}$ Although we did not measure cell mediated immunity in vivo, the lack of any correlation between anti-sperm antibodies and depressed $T$ cell numbers does not support this hypothesis. Neither does there appear to be any obvious correlation with HIV status.

In the present study it was interesting that antibody titres were lower than in the positive controls (infertile men). If the infertility was due to epididymal blockage with sperm granuloma formation, one could easily imagine that the level of antigenic exposure would be much higher than in men who were only exposed to sperm via the rectal mucosa. None of our subjects had undergone previous vasectomy.

It was also interesting that antibodies to sperm were only found in subjects who had recently been exposed to sperm (within the last six months), since IgG antibodies could reasonably be expected to persist longer, and most of our subjects had practised unprotected anal receptive intercourse at some stage in the previous six years, ${ }^{11}$ (and unpublished data).

There are other serological markers of homosexuality such as a high frequency of antibodies to cytomegalovirus, markers of hepatitis B infection, and past infection with syphilis, ${ }^{22}$ though we generally have to rely on skilled interviewers to validate risk factors for $\mathrm{HIV}^{23}$ Most, though not all, homosexual or bisexual men appear to acquire HIV infection through unprotected anal receptive intercourse. ${ }^{24}{ }^{25}$ At present we lack objective markers of this behaviour. A sensitive marker could be used in epidemiological studies in other populations endemic for HIV, for example to investigate whether Africans with HIV do not engage in receptive anal intercourse. Although the immunobead test as described may be too insensitive and cumbersome for this purpose, our findings nevertheless suggest a possible role for anti-sperm antibodies as a marker of receptive anal intercourse. However, further studies are needed to test this possibility more fully.

This study was supported by a grant from Family Health International, North Carolina 27709, USA. S.C. (C J Martin Fellow) and L.H. are supported by the National Health and Medical Research Council of Australia. The authors thank P Hayes of Melbourne Communicable Diseases Centre for obtaining sera, L Collins from Prince Henry's Hospital for help with the method and in recruiting sperm donors, and Ms Iras Collins for expert secretarial assistance.
Address for reprints: Dr B P Mulhall, Department of Public Health, University of Sydney, NSW 2006, Australia.

1 Alexander N, Anderson D. Immunology of semen. Fertil Steril 1987;47(2):192-201.

2 Wolf $\mathrm{H}$, Schill W. Antisperm antibodies in infertile and homosexual men: relationship to serological and clinical findings. Fertil Steril 1985;44(5):673-7.

3 Witkin S, Sonnabend J. Immune responses to spermatozoa in homosexual men. Fertil Steril 1983;39(3):337-42.

4 Witkin S, Bongiovanni A, Ru Ya I, et al. Humoral responses in healthy heterosexual, homosexual and vasectomised men, and in homosexual men with the Acquired Immunodeficiency Syndrome. AIDS Res 1983;1(1):31-34.

5 Adams LE, Donovan Brand R, Fieldman Kein A, et al. Sperm and seminal plasma antibodies in Acquired Immunedeficiency syndrome (AIDS) and other associated syndromes. Clin Immunol Immunopathol 1988;46:442-9.

6 Hargreave TB, Harvey J, Elton RA, McMillan A. Serum agglutinating and immobilising sperm antibodies in men attending a sexually transmitted diseases clinic. Andrologia 1984;16(2):111-5.

7 Witkin SS, Sonnabend J, Richards J, et al. Induction of antibody to asialo GMI by spermatozoa and its occurrence in the sera of homosexual men with the Acquired Immune-deficiency Syndrome (AIDS). Clin Exp Immunol 1983;54:346-50.

8 Richards J, Bedford T, Witkin S. Rectal insemination modifies immune responses in rabbits. Science 1984;224:390-2.

9 Mavligit GM, Talpaz M, Hsia F, et al. Chronic immune stimulation by sperm alloantigens: support for the hypothesis that spermatozoa induce immune dysregulation in homosexual males. JAMA 1984;251:237-41.

10 Barlow DH. Antisperm antibodies in infertility. Editorial, $\mathrm{Br}$ Med J 1988;296:310.

11 Mulhall BP, Carter L, Frazer IH. Immunologic and behaviourial changes in a cohort of homosexual men after five years, In: Abstracts, IV International Conference on AIDS, Stockholm 1988;II:216.

12 Clarke GN, Baker HWG. Detection of sperm antibodies using the immunobead test [IBT]. Aust J Med Lab Sci 1988;9: 66-70.

13 Centers for Disease Control. Classification Systems for human T-lymphotropic virus type III/lymphadenopathy-associated virus infections. MMWR 1986;35:334-9.

14 Rodman T, Laurence J, Pruslin F, et al. Naturally occurring antibodies reactive with sperm proteins, and apparent deficiency in AIDS sera. Science 1985;228:1211-5.

15 Tung KSK, Coroke WD, McCarty T, et al. Human sperm antigens and anti-sperm antibodies. II age related incidence of anti-sperm antibodies. Clin Exp Immunol 1976;25:73-9.

16 Mettler L, Czuppon AB, Alexander N, et al. Antibodies to spermatozoa and seminal plasma antigens detected by various enzyme-linked immunosorbent [ELISA] assays. J Reprod Immunol 1985;8:301-12.

17 Shearer GM, Hurtenbach U. Is sperm immunosuppressive in male homosexuals and vasectomized men? Immunol Today 1982;3:153-4.

18 Turner MJ, White J, Soutter WP. Seminal plasma and AIDS. Immunol Today 1987;8:258.

19 Mavligit GM, Talpaz M, Hsia F, et al. Chronic immune stimulation by sperm alloantigens: support for the hypothesis that spermatozoa induce immune dysregulation in homosexual males. JAMA 1984;251:237-41.

20 Alexander N, Anderson D. Immunology of semen. Fertil Steril 1987;47(2):192-201.

21 Mathur S, Goust JM, Williamson HO, et al. Cross-reactivity of sperm and T lymphocyte antigens. AJRI 1981;(1):113-8.

22 Potterat JJ, Muth JB. Markewick GS. Serological markers as indicators of sexual orientation in AIDS virus infected men. JAMA 1986;256:712.

23 Potterat JJ, Phillips L, Muth JB. Lying to military physicians about risk factors for HIV infection. JAMA 1987;257:1727.

24 Kingsley LA, Detels R, Kaslow R, et al. Risk factors for seroconversion to human immunodeficiency virus among male homosexuals. Lancet 1987;i:345-9.

25 Weber JN, McCreaner A, Berrie E, et al. Factors affecting seropositivity to human $T$ cell lymphotropic virus type III (HTLV-III) or lymphadenopathy associated virus (LAV) and progression of disease in sexual partners of patients with AIDS. Genitourin Med 1986;62:177-80.

Accepted for publication 18 October 1989 